\title{
Ability of RCM/GCM couples to represent the relationship of large scale circulation to climate extremes over the Mediterranean region
}

\author{
Helena A. Flocas ${ }^{1, *}$, Maria Hatzaki ${ }^{1,3}$, Konstantia Tolika ${ }^{2}$, Christina Anagnostopoulou ${ }^{2}$, \\ Effie Kostopoulou ${ }^{3}$, Christos Giannakopoulos ${ }^{3}$, Eleni Kolokytha ${ }^{1}{ }$, Ioannis Tegoulias ${ }^{2}$
}

\footnotetext{
${ }^{1}$ Department of Environmental Physics and Meteorology, Faculty of Physics, University of Athens, Build. Phys. V, 15784 Athens, Greece

${ }^{2}$ Department of Meteorology-Climatology, School of Geology, Aristotle University of Thessaloniki, 54124 Thessaloniki, Greece

${ }^{3}$ Institute for Environmental Research and Sustainable Development, National Observatory of Athens, I. Metaxa \& V. Pavlou Street, 15236 Athens, Greece
}

\begin{abstract}
The objective of this study was to explore the ability of 3 regional climate models (RCMs), CNRM-Aladin, C4I-RCA3 and KNMI-RACMO along with their parental global climate models (GCMs), ARPEGE and ECHAM5, to represent the relationship between large-scale atmospheric circulation and climate extremes in the Mediterranean region. Subsequently, an evaluation and inter-comparison of these $3 \mathrm{RCM} / \mathrm{GCM}$ couples for the present climate was performed. For this purpose, the Regularised Canonical Correlation Analysis (RCCA) was employed and 4 extreme climate indices of temperature and precipitation were used to define extreme events over the study region. The evaluation of these relationships was carried out against gridded observational and reanalysis datasets. It was found that the observed upper air large scale patterns related to climate extremes in the Mediterranean are not very well reproduced by the RCM/GCM couples in all seasons. In addition, in many cases, the coupled models display patterns of extreme climate indices which are not consistent with the accompanied upper level circulation. Furthermore, all coupled models display substantial deficiencies in simulating precipitation extremes. In the case of summer data, the ability of all 3 models is limited, possibly because the strength of the large-scale atmospheric flow decreases, the control exerted by the lateral boundary conditions is weaker, and the nested models are mainly governed by local processes.
\end{abstract}

KEY WORDS: Large scale circulation - Extreme climate indices - ENSEMBLES - Circulation patterns · RCCA $\cdot$ Regional climate models $\cdot$ Global climate models

\section{INTRODUCTION}

Understanding the physical processes that influence the occurrence of extreme events can be particularly important, since these events can generate important natural hazards and associated social impacts. In recent years, occurrence and intensity of climate extremes, under global climate change conditions have received increasing attention, especially at local and regional scales. One of most vulnerable regions to climate change is the Mediterranean (e.g. Hanson et al.
2007, Tolika et al. 2008, Giannakopoulos et al. 2009, Kostopoulou et al. 2009), since it lies in the transitional zone between North Africa and southern Europe.

The Mediterranean region is under the combined influence of large-scale circulation systems along with specific thermal and topographic characteristics (Meteorological Office 1962). It is characterised by extensive cyclonic activity in winter and spring (Maheras et al. 2001), while a large scale quasi permanent trough extends over the Mediterranean from southwest to northeast at the upper levels (Flocas et al. 2001). Three 
main areas of cyclogenesis with considerable intraannual variability are the Gulf of Genoa, southern Italy and Cyprus (Maheras et al. 2001), while Saharan depressions frequently affect the region mainly during spring (Prezerakos 1985). In summer, the subtropical Atlantic (Azores) anticyclone extends over the Mediterranean. The Asian thermal low predominates over the eastern Mediterranean along with a subtropical high pressure system above it at the $500 \mathrm{hPa}$ level and the related subsidence (Kostopoulou \& Jones 2007a).

Furthermore, many of the Mediterranean climatic features are associated with upper air circulation (Jacobeit 1987, Valero et al. 2004, Kostopoulou \& Jones 2007 b, Lolis et al. 2008), including the occurrence of extreme climate events (Baldi et al. 2006, Hatzaki et al. 2009, Oikonomou et al. 2010).

Drought episodes exhibit a remarkable increase in the Mediterranean throughout the whole year during the second half of the 20th century (Lloyd-Hughes \& Saunders 2002). Recent studies (Haylock \& Goodess 2004, Kostopoulou \& Jones 2005) show an increase of the maximum length of dry spells throughout the whole year over the last 4 decades and a significant decrease of winter precipitation in the eastern Mediterranean, while the western part is characterised by statistically significant positive trends in intense rainfall events. Remarkably significant trends of temperature extremes in the Mediterranean have been demonstrated in summer (Kostopoulou \& Jones 2005, Maheras et al. 2006). Furthermore, heat waves (defined as periods of consecutive days with daily maximum temperature exceeding a baseline threshold or specified percentile value) are a common feature of the Mediterranean summer, with varying intensities and lengths, that can affect human health and life and cause severe forest fires (Kostopoulou \& Jones 2005, Baldi et al. 2006, Tolika et al. 2009).

Global Climate Models (GCMs) are employed to perform projections of global climate, as a result of anthropogenic forcing. GCMs can simulate the largescale atmospheric circulation at a horizontal resolution of a few hundred kilometres (Rummukainen 2010). However, at this resolution, the effects of local and regional topography are not fully captured and the GCMs fail to reproduce the regional climatic features, especially climate extremes. Regional Climate Models (RCMs) driven at their lateral boundaries by data generated by GCMs, are employed instead. RCMs provide more detailed regional climatic information, consistent with the large scale circulation supplied by the driving GCMs (Giorgi \& Mearns 1999). Despite the finer resolution of RCMs, uncertainties in projected climate change are associated with model formulation, including parameterisation schemes (Bergant et al. 2007, Sanchez-Gomez et al. 2009). These uncertainties are most prominent in terms of precipitation, especially in regions characterised by complex terrain, such as the Mediterranean (Zanis et al. 2009). In addition, the lateral forcing of the RCMs by the driving GCMs introduces an additional source of uncertainty. Even forced by the same GCM, RCMs may simulate different circulation patterns within the domain, making probability estimates of future extreme events very uncertain (van Ulden \& van Oldenborgh 2006). This variability is often called internal variability. It is weaker in midlatitudes, but stronger in summer when the local processes are more dominant than the large scale circulation (SanchezGomez et al. 2009 and references therein).

Therefore, it is essential that the RCMs combined with the driving GCMs should be able to represent large scale patterns related with the occurrence of climate extremes in a specific region (e.g. Hanson et al. 2007). LucasPicher et al. (2008) concluded that an increased domain size reduces the influence of the driving field on the RCM simulations and enhances the internal variability, especially in winter. On the other hand, Sanchez-Gomez et al. (2009) - examining the ability of the ENSEMBLES ERA40-forced RCMs to reproduce at a large-scalefound that all RCMs reproduce very well the composite pattern of weather regimes. To address questions concerning the ability of climate models to represent climate extremes in the present and future climate, it is necessary to explore the link between local extremes and large-scale circulation features.

The main scope of this study was to evaluate and intercompare the ability of $3 \mathrm{RCM} / \mathrm{GCM}$ couples to reproduce the large scale circulation at $500 \mathrm{hPa}$ level over the greater European-Atlantic region linked with climate extremes (namely, cold and warm extremes, heavy precipitation events, and extremely long dry spells) in the Mediterranean region, with the aid of the Regularised Canonical Correlation Analysis (RCCA). The evaluation was performed using results derived from the same analysis method with gridded observations and NCEP/ NCAR Reanalysis data. Such an evaluation may explain results of GCM dynamical downscaling for future projections of climate extremes in the Mediterranean region. The model datasets became available through the European project ENSEMBLES (www.ensembleseu.org), which aims to quantify the uncertainty in longterm predictions of climate change with emphasis on probable future changes in climate extremes.

\section{DATA AND METHODS}

Daily precipitation and temperature data from the 3 RCMs were employed for the period 1950-2000 with a spatial resolution of $0.25^{\circ} \times 0.25^{\circ}$ : CNRM-Aladin (Radu et al. 2008), C4I-RCA3 (Kjellström et al. 2005) and 
KNMI-RACMO2 (van Meijgaard et al. 2008). Moreover, $500 \mathrm{hPa}$ geopotential heights (Z500) data were employed for the greater European Atlantic region, derived from the 2 parental GCMs ARPEGE and ECHAM5 datasets. The ARPEGE provides results for the period $1950-1999$ on a $2.8^{\circ} \times 2.8^{\circ}$ grid approximately (Déqué et al. 1994) and ECHAM5 for the period $1950-2000$ on a $1.85^{\circ} \times 1.875^{\circ}$ grid approximately (Roeckner et al. 2006).

Although a wider set of models was available within the context of ENSEMBLES (see www.ensebles-eu.org), we selected a subset of 3 RCMs driven by 2 GCMs. In this way, we can directly compare the 2 RCMs (C4IRCA3 and KNMI-RACMO) driven by the same GCM (ECHAM5), thus identifying differences in extremes caused by the dynamical downscaling in the RCMs. Then we can compare the RCMs (CNRM-Aladin with C4I-RCA3 and KNMI-RACMO) driven by different GCMs (ARPEGE and ECHAM5, respectively) to visualise the importance of large scale patterns in reproducing extremes.

The same version of ECHAM5 has been used by all ENSEMBLES partners to drive their RCMs. However, the Max Planck Institute has created 3 different ensemble members with their ECHAM5.2.02a. These are referred to as r1, r2 and r3. The C4I-RCA3 has been driven by the first member of that ensemble, called r1, while KNMI-RACMO used ECHAM5-r3. Therefore, the 2 members are expected to be slightly different, but since the ECHAM model version is the same and the differences only arise from the choice of a different ensemble member of ECHAM, it makes sense to compare the 2 RCMs, especially when looking at long-term climate averages and statistics (T. Semmler pers. comm.). Moreover, in the context of the present study, we performed comparisons of the $500 \mathrm{hPa}$ geopotential height monthly averages of the 2 ECHAM members during the examined period that demonstrated nonsignificant biases over the greater European and eastern Atlantic region (not shown).

The isobaric level of $500 \mathrm{hPa}$ was selected, as representative of upper levels, where important dynamic factors, largely independent of topography, affect the temperature and precipitation regimes. The selected domain for which Z500 is investigated covers a window extending from $20^{\circ} \mathrm{W}$ to $50^{\circ} \mathrm{E}$ and from $20^{\circ}$ to $65^{\circ} \mathrm{N}$ (Fig. 1a).

Extreme climate events are described using indices that cover both frequency and intensity description of extreme processes. In this study, the following climate indices were selected: (1) the 90th percentile of maximum temperature (TXQ90) for warm extremes, (2) the 10th percentile of minimum temperature (TNQ10) for cold extremes, (3) the 95th percentile of precipitation amounts (PQ95) of wet-days amounts (where a wet day is defined as having rainfall of at least $1 \mathrm{~mm}$ ), representing intense precipitation events, and (4) the consecutive dry days (CDD) during a specific period of time representing extremely long dry spells (where a dry day is defined as having no rainfall or rainfall $<1 \mathrm{~mm}$ ). These indices belong to the core indices suggested by the European Project STARDEX (STAtistical

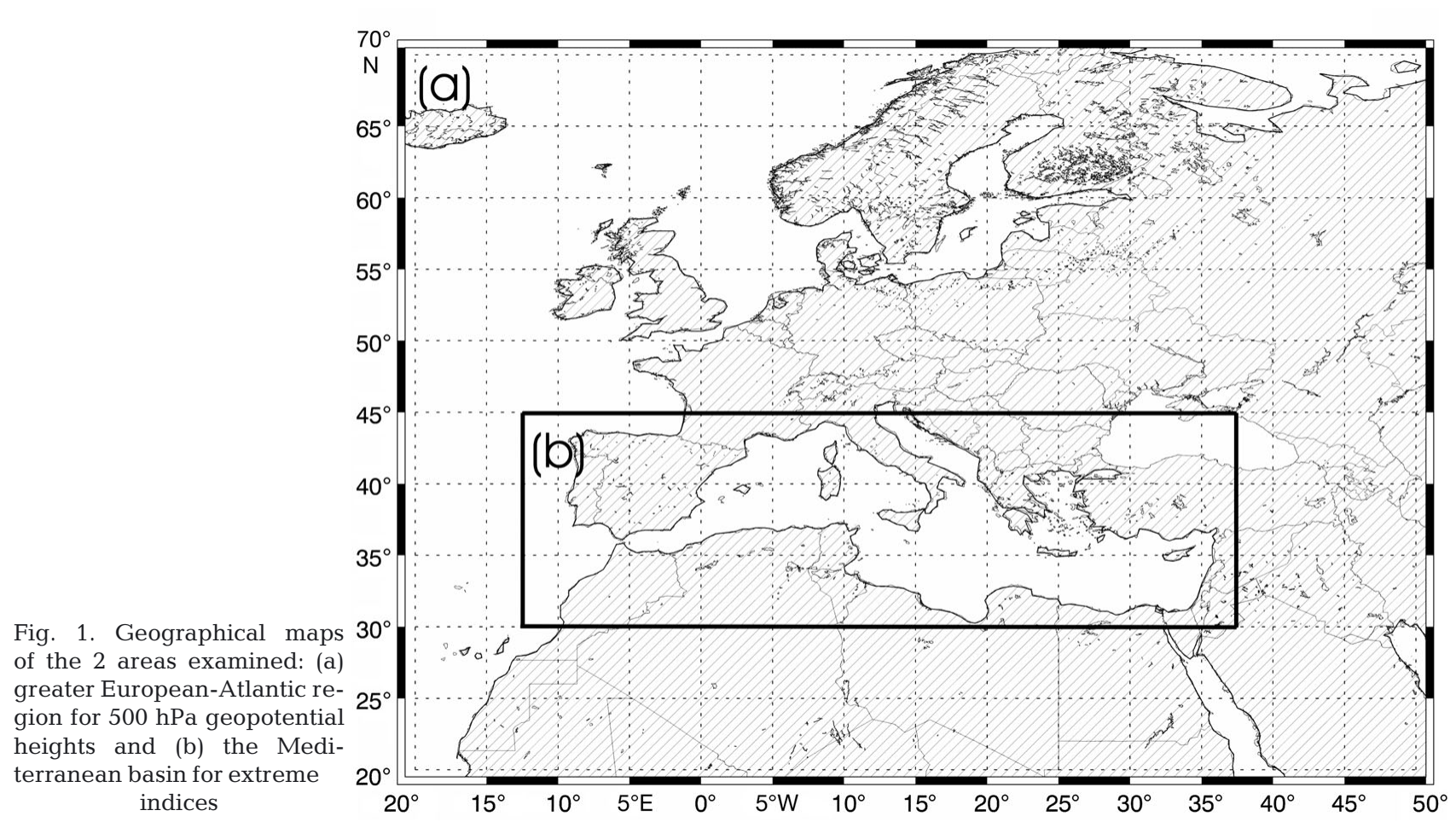


and Regional Dynamical downscaling of EXtremes for European regions) to encompass magnitude, frequency and persistence of extremes. They have been employed in previous studies for a range of climatic regimes experienced across Europe (e.g. Haylock et al. 2006, Tolika et al. 2008) and are considered as moderate climate extremes indicators providing larger statistical confidence compared to indices looking at more extreme events (Haylock \& Goodess 2004).

These indices were calculated from the daily maximum and minimum temperatures, and precipitation on a seasonal basis for the 1950-2000 period over the Mediterranean region (including the sea), separately for the 3 regional models and the gridded observations. The domain for which the climate indices were calculated extends from $12.5^{\circ} \mathrm{W}$ to $37.5^{\circ} \mathrm{E}$ and from $30^{\circ}$ to $45^{\circ} \mathrm{N}$ (Fig. 1b).

The relationship between the large scale circulation and the climate extremes was explored by applying Regularised Canonical Correlation Analysis (RCCA). The principle of Regularized CCA was first proposed by Vinod (1976) and further developed by Leurgans et al. (1993). In general, CCA identifies a sequence of pairs of patterns in 2 multivariate data sets, and constructs new variables - called canonical variates - that maximise the interrelationships, i.e. the canonical correlations, between the 2 datasets. The canonical variates are linear combinations of the variables of each data set, e.g. Z500 and each extreme index, respectively. The canonical correlation between the successively extracted pairs of the canonical variates is an overall index of the correlation between each 2 sets of variables and becomes smaller in successive pairs. With large sample sizes, the first canonical correlation magnitudes of 0.30 will become statistically significant.

RCCA is applied to seek correlations between 2 data set matrices $\mathrm{X}, \mathrm{Y}$, when the number of the variables, namely the number of grid points of the Z500 and the extreme indices fields, arithmetically exceed the length of the data series. As the number of grid points increases, the greatest canonical correlations are close to unity and, as a consequence, do not provide any meaningful information. To confront this problem a regularisation step is introduced in the calculations by adding a regularisation parameter $\lambda_{1}, \lambda_{2}$ on the diagonal of each correlation matrix of $\mathrm{X}$ and $\mathrm{Y}$, respectively (Leurgans et al. 1993).

In this study, the RCCA was performed using the R statistical language (González et al. 2008) applied to each RCM/GCM couple for the 1950-2000 period (1950-1999 for the CNRM couple). Specifically, the analysis was performed between the seasonal data series for each of the 4 indices and for each regional model and the seasonal data series of Z500 and for the corresponding parental GCM. The RCM/GCM couples are: CNRM-Aladin and ARPEGE, KNMIRACMO2 and ECHAM5-r3, C4I-RCA3 and ECHAM5r1. Hereafter, the terms CNRM, KNMI and C4I will refer to each RCM/GCM couple, as well as to their corresponding RCCA combined results.

The model RCCA results are evaluated against the corresponding data derived from daily geopotential heights at $500 \mathrm{hPa}$ available from the NCEP/NCAR Reanalysis Database provided by the National Oceanic and Atmospheric Administration (www.cdc.noaa.gov), and from daily precipitation and temperature gridded observational datasets (E-OBS) over the Mediterranean (Haylock et al. 2008). These results will be referred to hereafter as 'observed'. The gridded datasets have been developed in the framework of the ENSEMBLES project, on the basis of a European network of high quality station series (http://eca.knmi.nl) and cover the period $1950-2000$, available on a $0.25^{\circ}$ and/or $0.5^{\circ}$ regular latitude/longitude grid, as well as on $0.22^{\circ}$ and/or $0.44^{\circ}$ rotated pole grid. These datasets are constructed at exactly the same rotated grid that 2 of the models are running at (C4I and KNMI), while CNRM operates on a different grid. This fact could affect the interpretation of the results when a point by point evaluation is performed, although in our study only the spatial distribution of the results is considered.

The dataset covers Europe and a part of North Africa, for the greater part with a resolution high enough to capture extreme weather and climate events. However, in areas where relatively few stations have been used for the interpolation, both precipitation and temperature are oversmoothed, especially when extremes are considered (Hofstra et al. 2009).

For the ENSEMBLES RCMs, an exploratory set of metrics for a derivation of RCM weights was designed using ERA-40 driven RCM simulations and the E-OBS gridded observations, including temperature and precipitation extremes. This is an important step in quantifying RCM behaviour. These metrics are conditional on the quality of the underlying driving and observational data, which is particularly important for the calculation of extremes (van der Linden \& Mitchell 2009). The evaluation of the representation of extremes in RCMs, in the framework of the ENSEMBLES Project, focused mainly on the European region and the derived results varied greatly between sites. In some cases, all models performed adequately, while for other sites some models did better than others (van der Linden \& Mitchell 2009).

\section{RESULTS}

The first 2 canonical pairs derived from the observed datasets are presented separately for each index and 


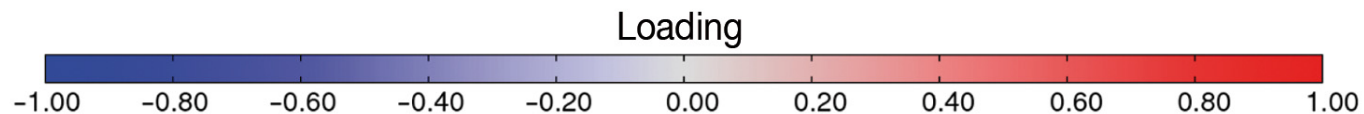

(a) OBS
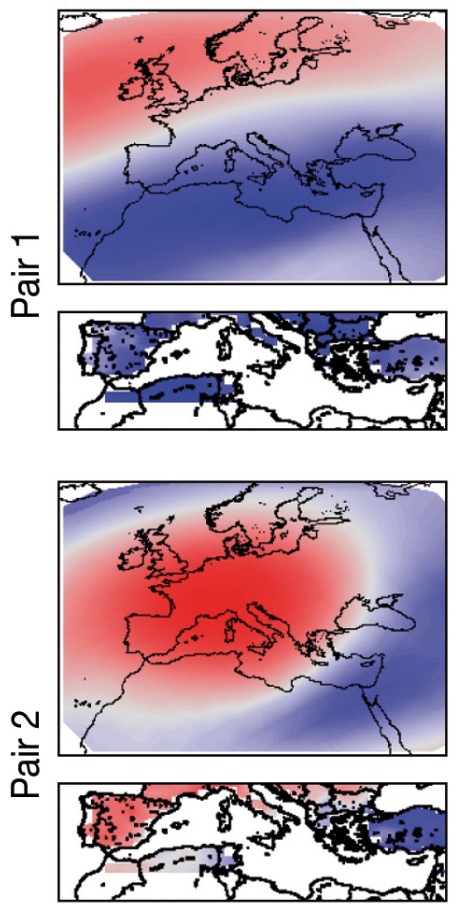

(b) CNRM
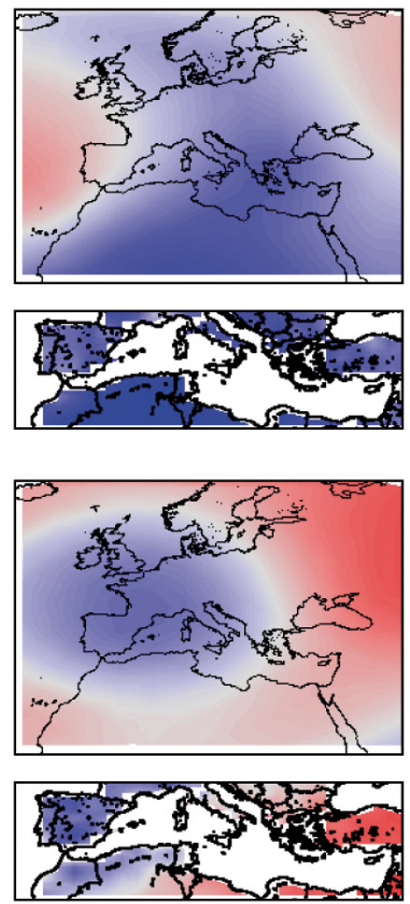

(c) $\mathrm{C} 4 \mathrm{I}$
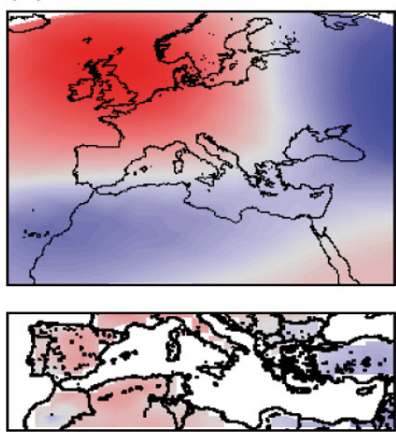

(d) KNMI
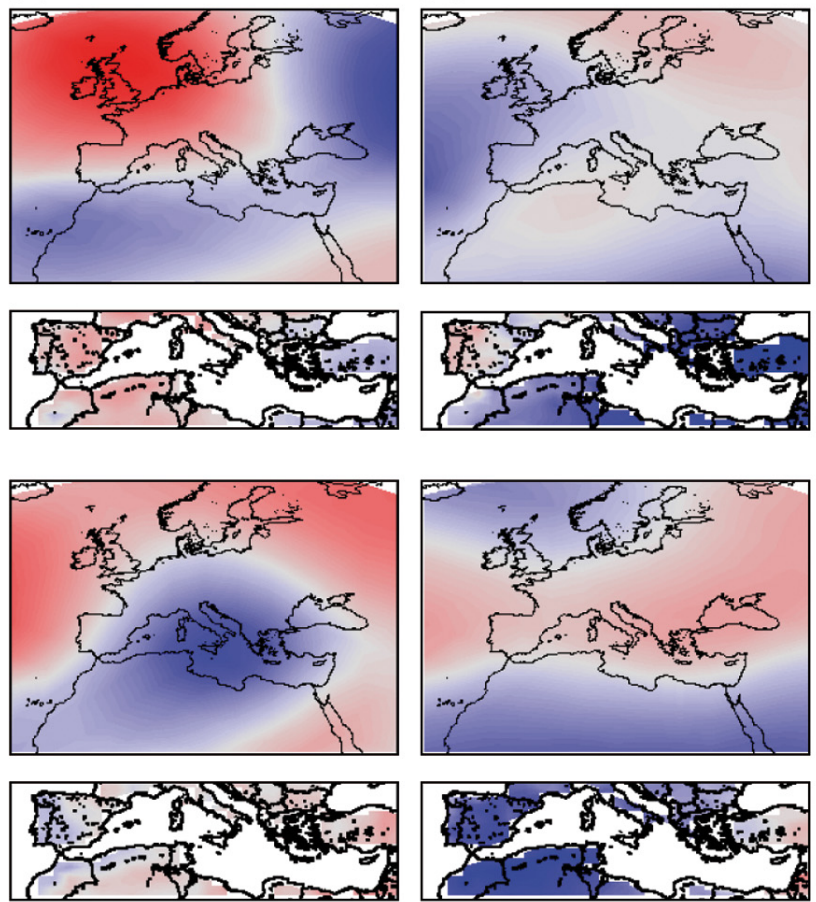

Fig. 2. Canonical loadings for the first 2 canonical pairs of Z500 (upper panels) and maximum temperature (TXQ90) during winter (lower panels) for (a) gridded observations (OBS), (b) CNRM, (c) C4I and (d) KNMI couple

then the corresponding results derived from the 3 RCM/GCM couples are evaluated and inter-compared on a seasonal basis. In RCCA there is no explicit criterion regarding the number of canonical pairs to be retained other than the statistical significance of the canonical correlation of each pair. A large number of pairs in each case are considered significant, though for easier interpretation of the results, the first 2 pairs were retained for each index and each season; plots of the canonical loadings are provided for the first 2 pairs. The canonical loadings represent the Pearson correlations between the initial variables and the canonical variates. In other words, the spatial distribution of the loadings provides a measure of the correlation of each initial variable (i.e. grid point) with the resulting canonical variate. High loadings indicate that the corresponding variables (e.g. the data series of the corresponding grid points) are highly correlated with the canonical variate and thus, have more in common with it. In this way we can infer in which areas, the two fields (Z500 and extreme index) are highly correlated and in which manner. It should be mentioned that the signs of the loadings are arbitrary and could be interpreted in the reverse sense.

\subsection{0th percentile of maximum temperatures (TXQ90)}

The observations for winter show that negative (positive) anomalies of geopotential heights over the Mediterranean region lead to a reduction (increase) of warm extremes (Fig. 2a, Pair 1). The negative anomalies correspond to the intensification of the typical cyclonic circulation pattern at $500 \mathrm{hPa}$ during winter (Lolis et al. 2008). When a blocking system over large parts of Europe is combined with cyclonic circulation to the east of the area, a dipole structure forms over the Mediterranean resulting in an increase of warm events over the western part and in a decrease over the eastern part (Fig. 2a, Pair 2).

During summer the observations (Fig. 3a) with positive loading signs indicate that the prevailing pattern of large scale circulation consists of positive Z500 anomalies over the greater European region and represents the dominance of the subtropical anticyclone (Lolis et al. 2008). This pattern is accompanied by positive extreme index anomalies in the whole Mediterranean region (Fig. 3a, Pair 1). An east-west dipole structure in the Z500 anomalies is accompanied by a 


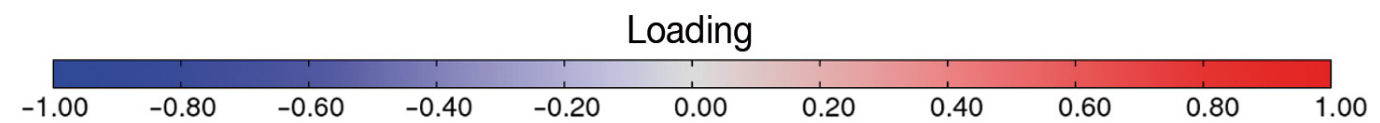

(a) OBS
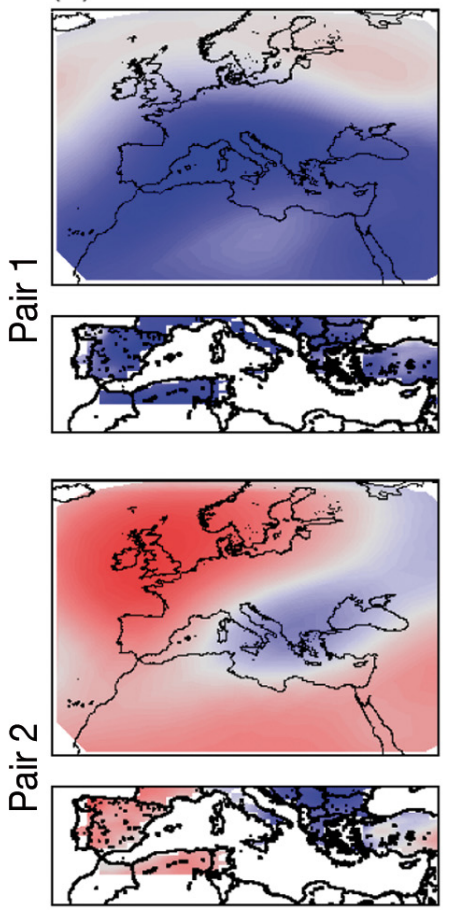

(b) CNRM
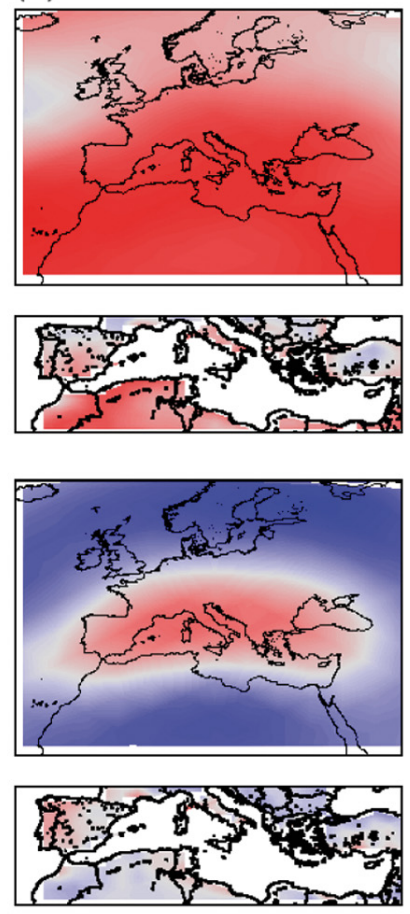

(c) $\mathrm{C} 4 \mathrm{I}$
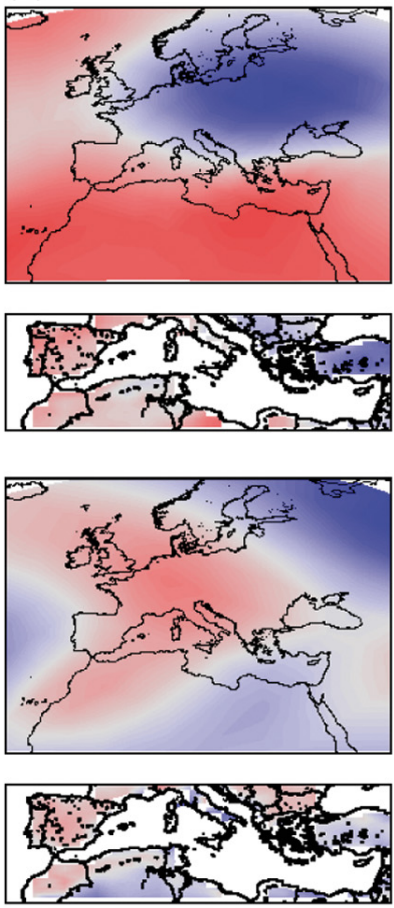

(d) KNMI
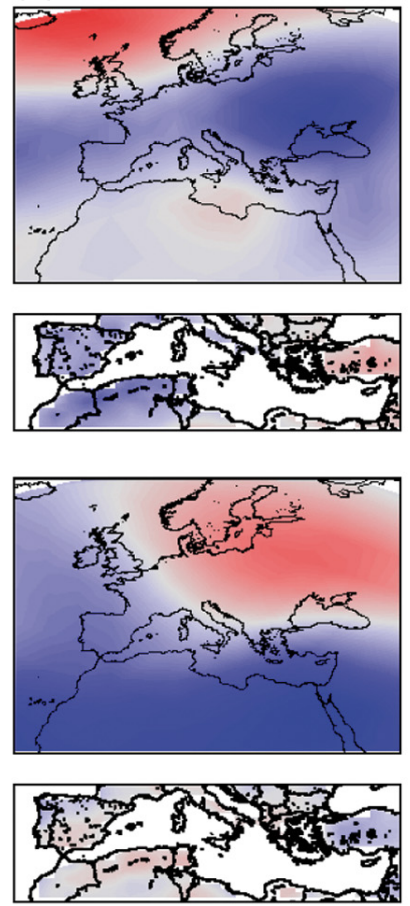

Fig. 3. Canonical loadings as in Fig. 2, but for maximum temperature (TXQ90) during summer

corresponding east-west distribution of TXQ90 anomalies (Fig. 3a, Pair 2). These patterns reflect summertime cyclones passing over central and eastern Mediterranean (Spanos et al. 2003).

Regarding the models' ability to reproduce the observed pairs, it is evident that during winter, all models exhibit a dipole structure at Z500 filed between the northwestern and southeastern parts of European region, though CNRM large scale circulation seems to better explain the TXQ90 spatial distribution over the Mediterranean (Fig. 2b, Pair 1). Pair 2 of CNRM describes cyclonic (anticyclonic) anomalies over southern Europe linked to decreases (increases) of extreme maximum temperatures of the adjacent areas, in agreement with the observed data.

Accordingly, during summer, the CNRM large scale circulation seems to explain well the extreme maximum temperature patterns for both CCA pairs (Fig. 3b). In this season, C4I large scale patterns are consistent with the observed results, but not entirely consistent with the regional scale patterns; while the canonical loadings of TXQ90 demonstrate spatial variations of different magnitude across the Mediterranean (Fig. 3c). For CNRM, especially, increased geopotential height values lead to increased maximum temperatures mainly over North Africa, Spain and Italy (Fig. 3b, Pair 1). In all models, increased anticyclonic circulation over southern, northeastern or northwestern Europe induces an increase in the extreme maximum temperature over a major part of the Mediterranean (Fig. 3b, Pair 2).

In general, CNRM performs better in reproducing the observed patterns in all seasons, compared to the other 2 models. The canonical loadings are stronger for KNMI and CNRM, compared to C4I, and are more uniform across the Mediterranean, especially during spring and autumn (not shown).

\subsection{0th percentile of minimum temperatures (TNQ10)}

The examination of the observed results (Fig. 4a) during winter indicates that the most prominent pattern, as in extreme maximum temperature (Fig. 3), is an increased anticyclonic (cyclonic) circulation over the greater part of the Mediterranean, leading to increased (decreased) anomalies of TNQ10 (Fig. 4a, Pair 1), respectively. The European blocking (Pelly \& Hoskins 2003), combined with cyclonic anomalies to the east, involves opposite sign anomalies between the western and the eastern Mediterranean regions (Fig. 4a, Pair 2). 


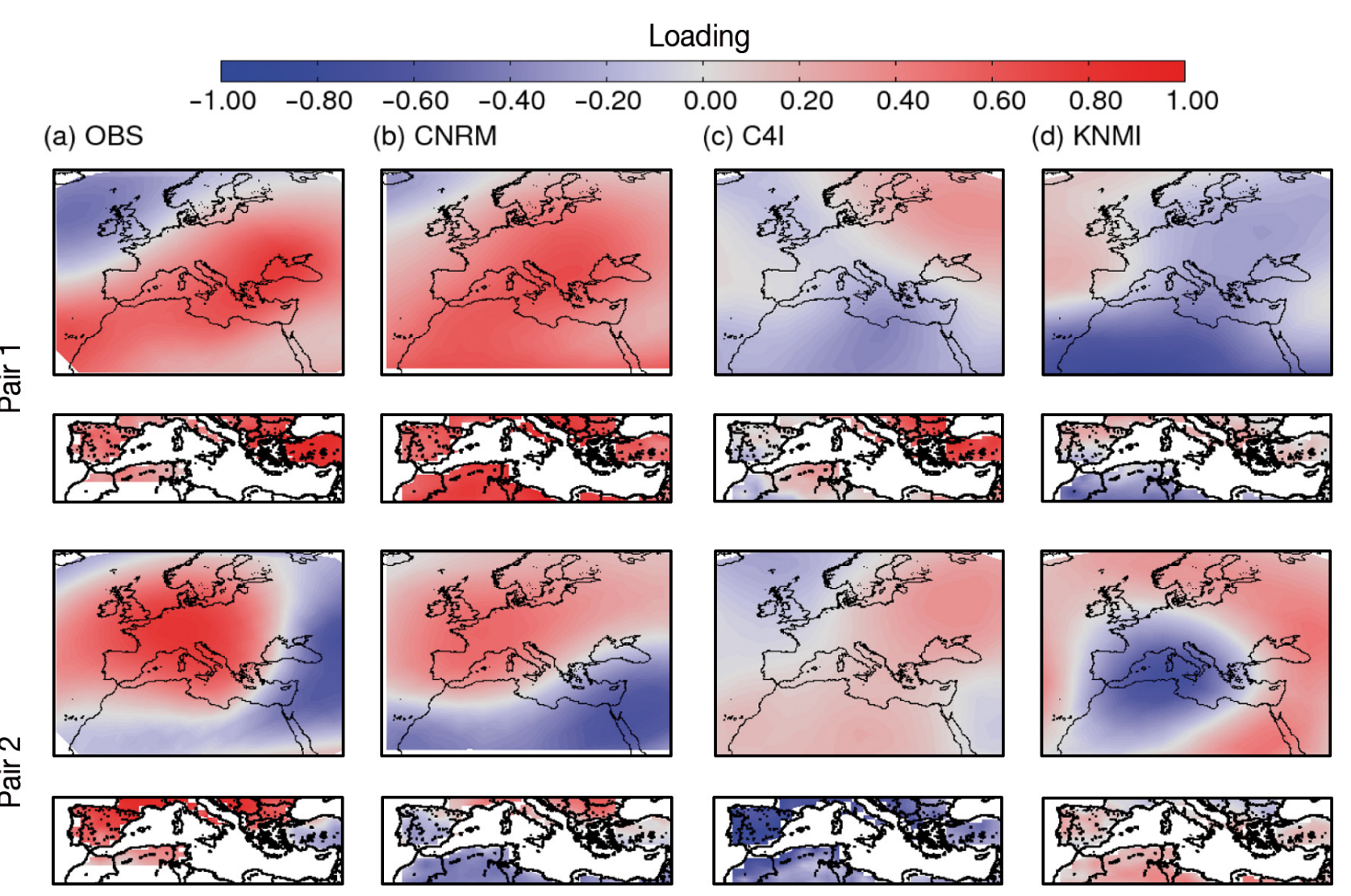

Fig. 4. Canonical loadings as in Fig. 2, but for minimum temperature (TNQ10) during winter

During summer, anticyclonic (cyclonic) anomalies over the entire examined area generate increased (decreased) anomalies of extreme minimum temperatures over the greatest part of Mediterranean (Fig. 5a, Pair 1), while an east-west dipole on Z500 anomalies over Europe is accompanied with a similar TNQ10 anomalies dipole over the Mediterranean (Fig. 5a, Pair 2).

Model evaluation revealed that CNRM compares very well with observations; in CNRM the patterns of TNQ10 are more consistent with the $500 \mathrm{hPa}$ geopotential height circulation. In all models the European blocking is the most prominent pattern of atmospheric circulation. From the model inter-comparison, it can be seen that C4I and KNMI exhibit similar large scale patterns, with weak loadings for C4I, followed by similar patterns in minimum temperature extremes for winter (Fig. 4c,d).

In general, the models exhibit similar behaviour with the corresponding TXQ90 results, with CNRM having the best performance and C4I having a better ability compared to KNMI.

\subsection{5th percentile of precipitation amounts (PQ95)}

The analysis of the observed pairs for extreme precipitation events during winter (Fig. 6a) indicates the existence of an intense cyclonic centre over Western Europe (Pair 1) the leading to an enhancement of extreme precipitation events in parts of western Mediterranean. This pattern is consistent with the surface circulation prevailing during wet spell anomalies in the western Mediterranean (Maheras et al. 1999), except for some regions, e.g. Spain in Fig. 6d. An extended cyclonic circulation over the greater Mediterranean region leads to overall increased extreme precipitation anomalies (Fig. 6a, Pair 2), consistent with anomalous low pressure, southerlies and enhanced precipitation in the Eastern Mediterranean (Eshel \& Farrell 2000). The patterns of PQ95 are consistent with the large scale circulation, as the positive (negative) Z500 anomalies are linked to negative (positive) intense precipitation amounts.

A common winter pattern related to the PQ95 in the CNRM and C4I models appear as Pair 1 for CNRM (Fig. 6b) and Pair 2 for C4I, with inverse sign and very weak loadings (Fig. 6c). Furthermore, C4I and KNMI present similar large scale patterns, though with weak loadings for C4I, followed by similar patterns in extreme precipitation amounts (Fig. 6c,d).

In summer, the CNRM (Fig. 7b) again seems to better reproduce the large scale circulation derived from the observed data (Fig. 7a), i.e. negative (positive) 


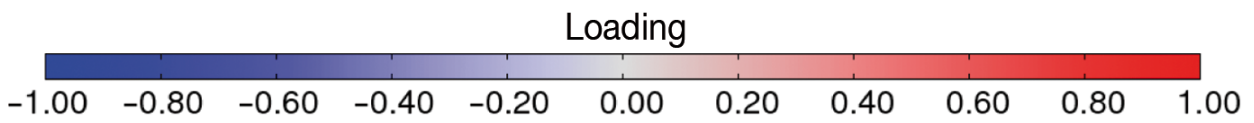

(a) OBS
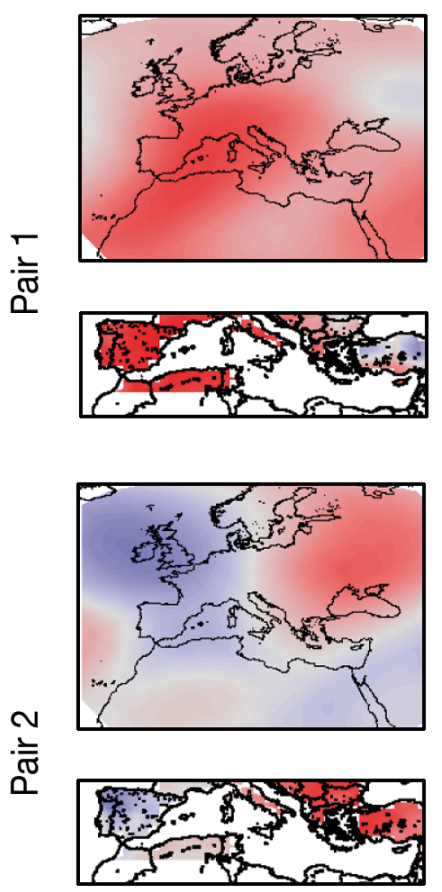

(b) CNRM
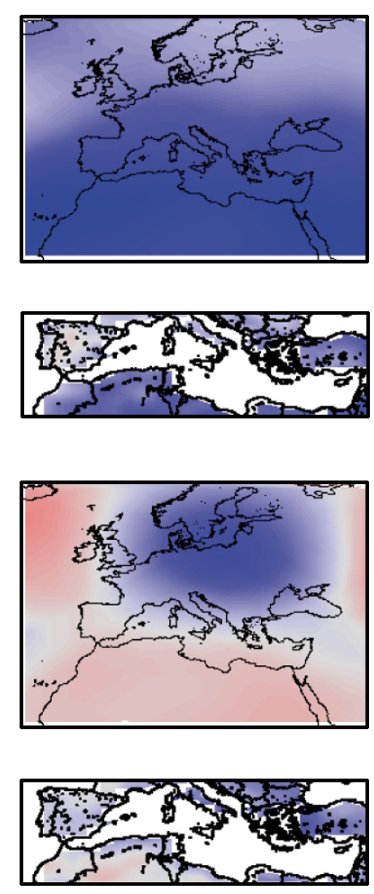

(c) $\mathrm{C} 4 \mathrm{I}$
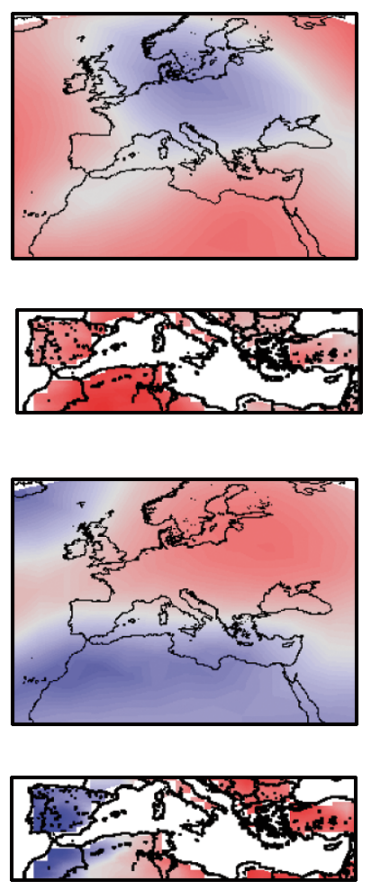

(d) KNMI
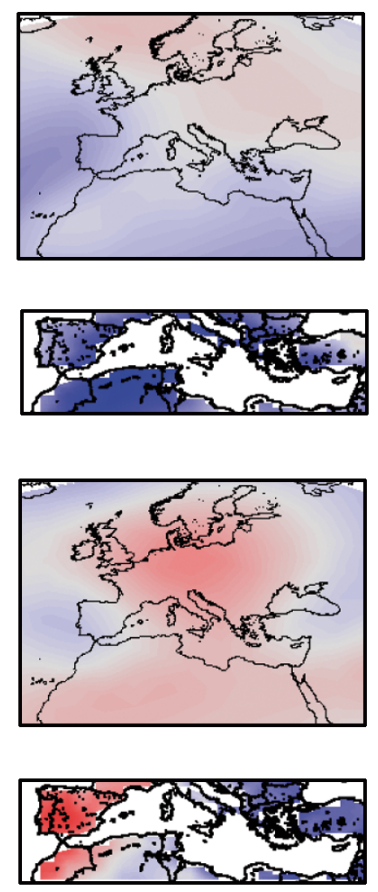

Fig. 5. Canonical loadings as in Fig. 2, but for minimum temperature (TNQ10) during summer

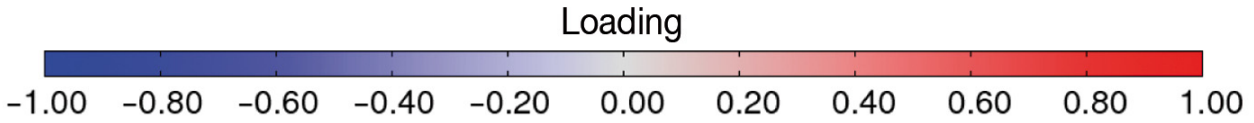

(a) OBS
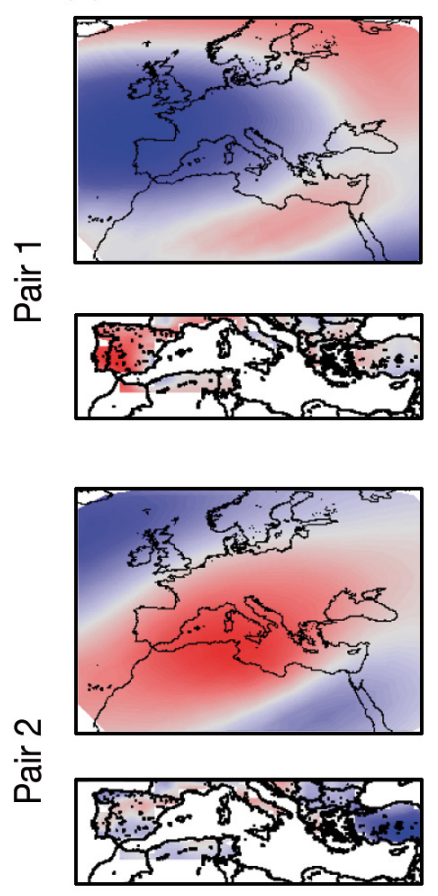

(b) CNRM
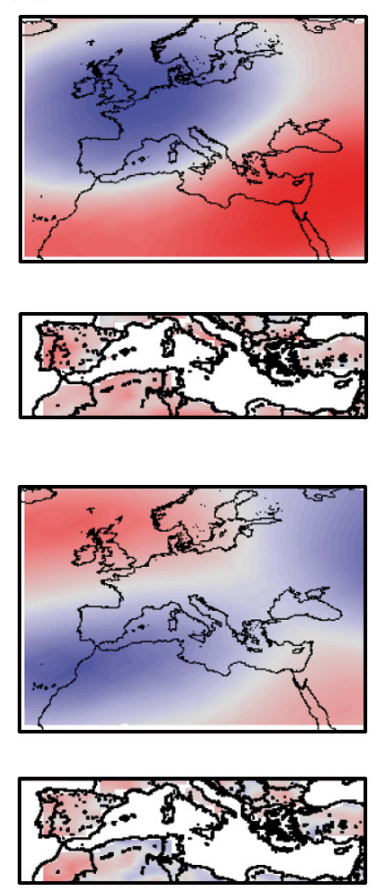

(c) $\mathrm{C} 4 \mathrm{I}$
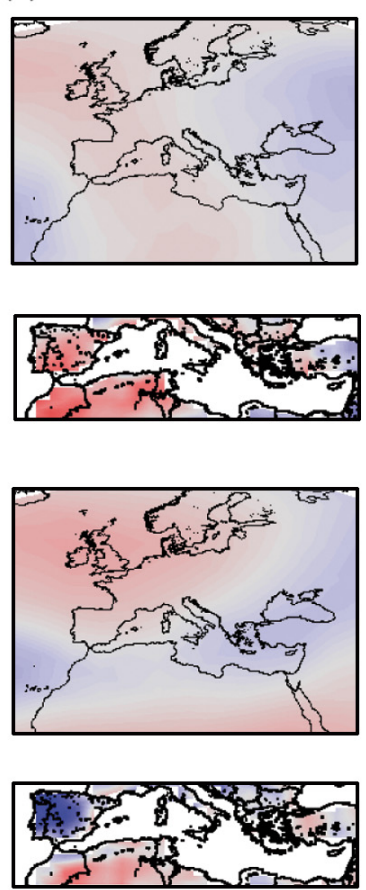

(d) KNMI
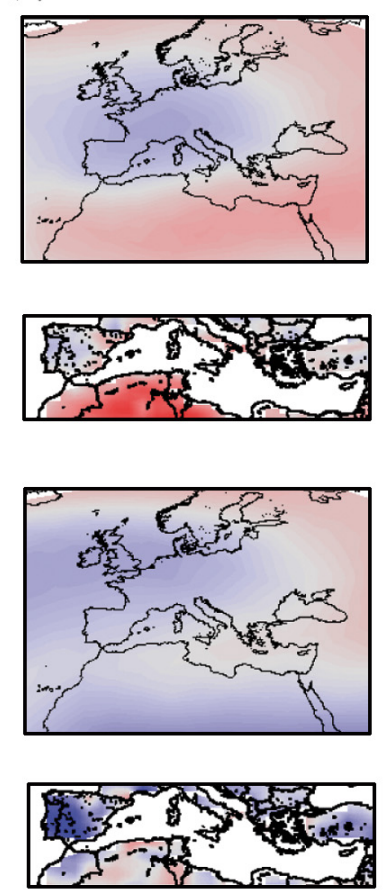

Fig. 6. Canonical loadings as in Fig. 2, but for precipitation (Q95) during winter 


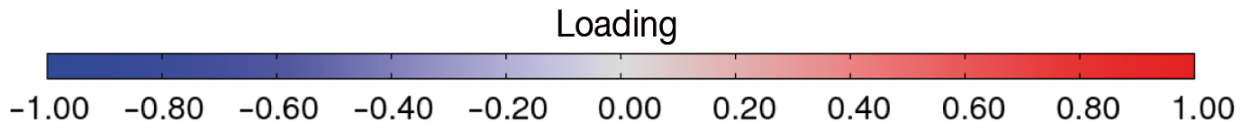

(a) OBS
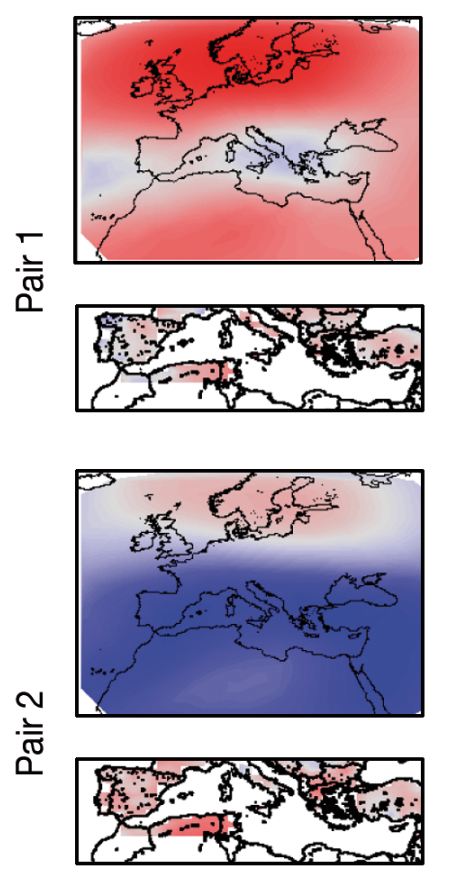

(b) CNRM
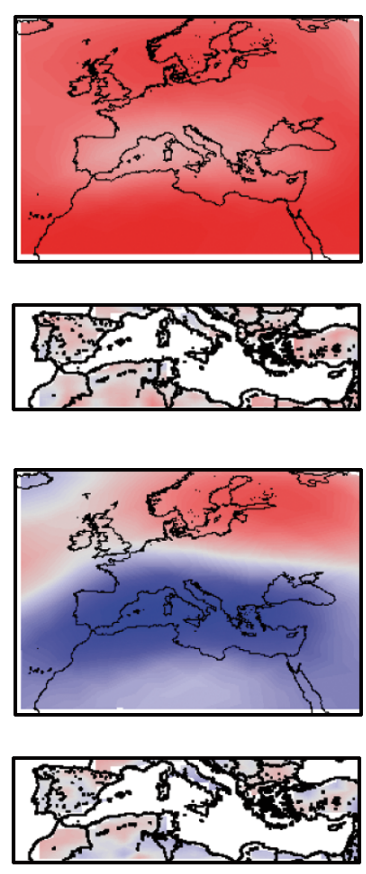

(c) $\mathrm{C} 4 \mathrm{I}$
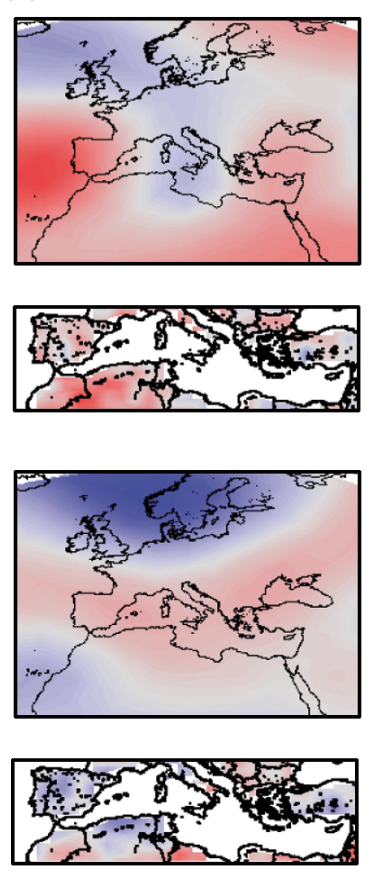

(d) $\mathrm{KNMI}$
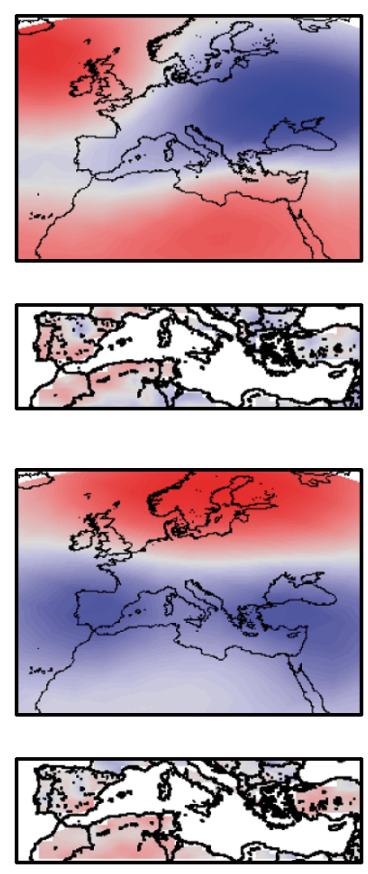

Fig. 7. Canonical loadings as in Fig. 2, but for precipitation (PQ95) during summer

anomalies of geopotential heights that are prominent over the Mediterranean lead to an increase (decrease) in intense precipitation events (Fig. 7b).

In general, the results regarding the index surface patterns vary among the 3 models, a fact that could be attributed to a low skill of the models in simulating precipitation as described in previous studies (Fowler et al. 2007, Chen \& Knutson 2008). However, CNRM again exhibits better ability in reproducing the observed pairs. Furthermore, the sign of the loadings of the index varies spatially across the Mediterranean, while the Z500 loadings are relatively weak in many cases indicating the possible inability of the models and/or of the method to capture the relationship between large scale circulation and precipitation extremes. Besides, the upper level circulation does not play as significant a role as the surface circulation in the precipitation regime (Maheras et al. 2004).

\subsection{Consecutive dry days (CDD)}

In winter, the observed data (Fig. 8a, Pair 1) identify an anticyclonic circulation over Europe and the Atlantic, which is responsible for an increase of extremely long dry spells over the Mediterranean
(Fig. 5b), in agreement with the results of Oikonomou et al. (2010), who employed a different multivariate method for the western Mediterranean. CNRM produced a similar pattern in Fig. 8b, Pair 1, verifying its ability during this season, similar to the other indices. C4I is also capable of capturing the 2 pairs (Fig. 8c), while KNMI exhibits weak loadings (Fig. 8d).

In summer, the observed data indicate the predominance of an anticyclonic anomaly over the Mediterranean, representing the subtropical high over the Mediterranean and southern Europe, as well as of the Azores high over the Atlantic (Fig. 9a, Pair 1) (see also Oikonomou et al. 2010). C4I (Fig. 9c) reproduces the observed patterns (Fig. 9a), contrary to the other 2 models. Moreover, C4I provides more consistent results between the 2 fields, reflecting a better simulation for this index in summer (Fig. 9c). KNMI exhibits very weak loadings and forms quite dissimilar patterns, indicating an inability of the model and/or the method to capture the relationship between large scale circulation and extreme dry spells. It is worth noting that KNMI-RAMCO and C4I-RCA3 are driven by the same parental GCM (ECHAM5), but still present different patterns. We should have in mind that the 2 RCMs are driven by different ensemble members of ECHAM5 (r1 and r3), as mentioned in Section 2. The inconsistencies 


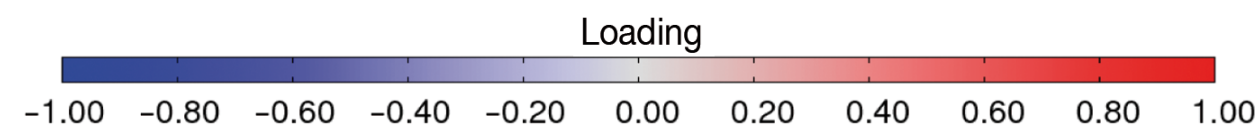

\section{(a) OBS}

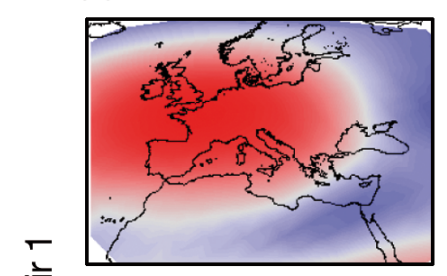

$\overline{\mathrm{N}}$
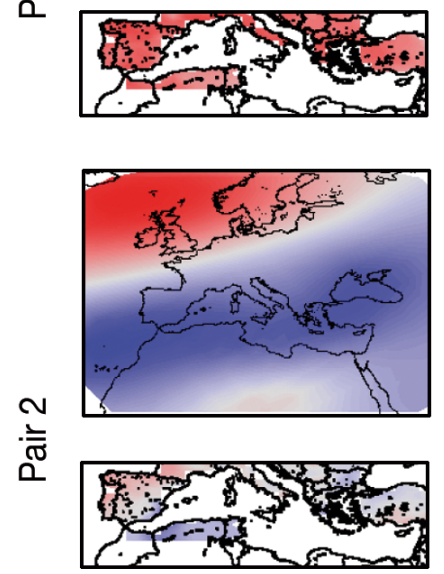

(b) CNRM
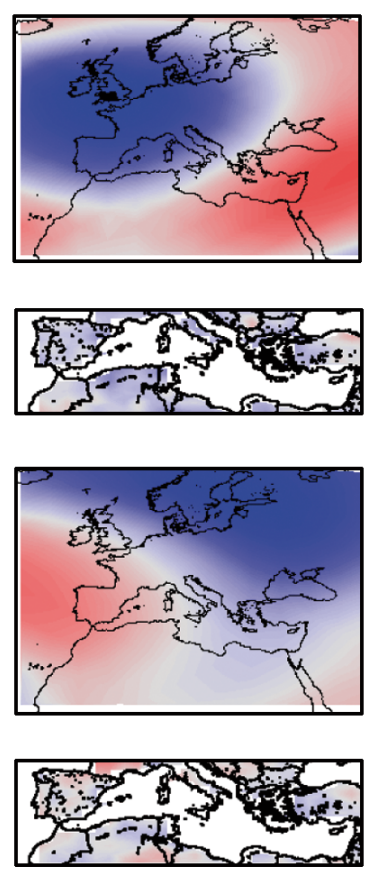

(c) $\mathrm{C} 4 \mathrm{I}$
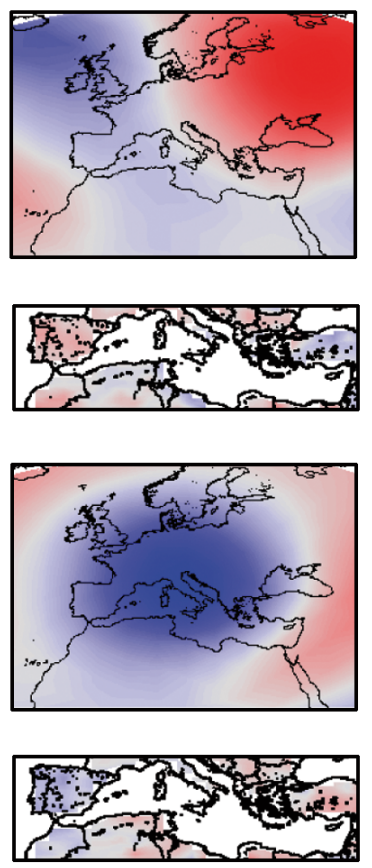

(d) $\mathrm{KNMI}$
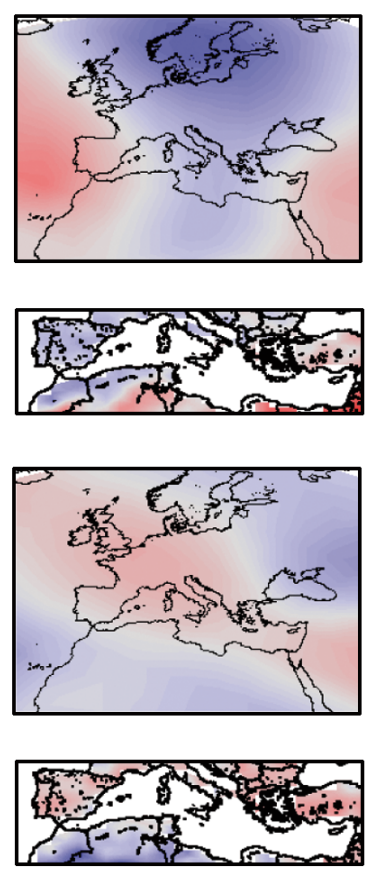

Fig. 8. Canonical loadings as in Fig. 2, but for consecutive dry days (CDD) during winter

Loading

(a) OBS

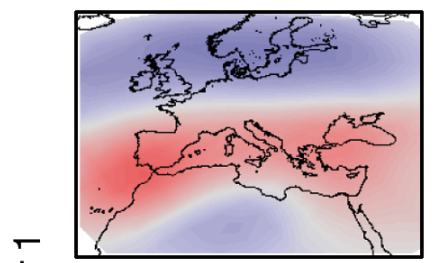

言
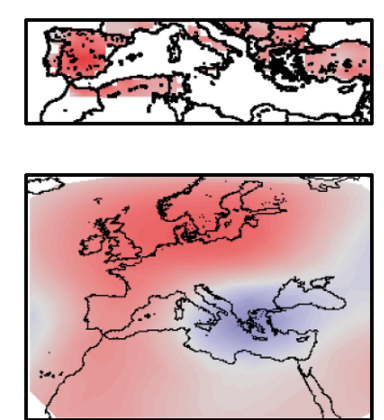

$\stackrel{\frac{1}{\bar{\sigma}}}{\circ}$

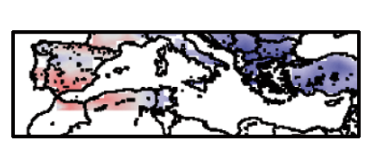

(b) CNRM
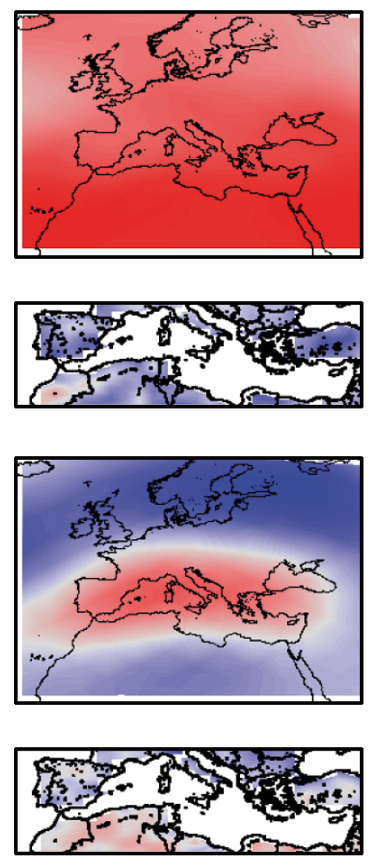

$\begin{array}{llllll}0.00 & 0.20 & 0.40 & 0.60 & 0.80 & 1.00\end{array}$

(c) $\mathrm{C} 4 \mathrm{I}$
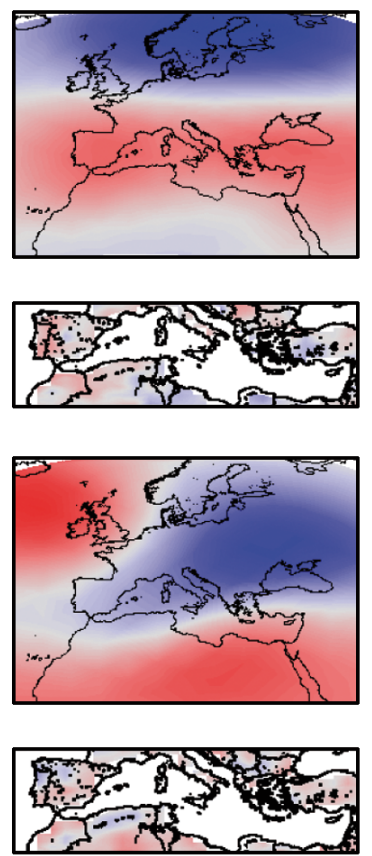

(d) KNMI
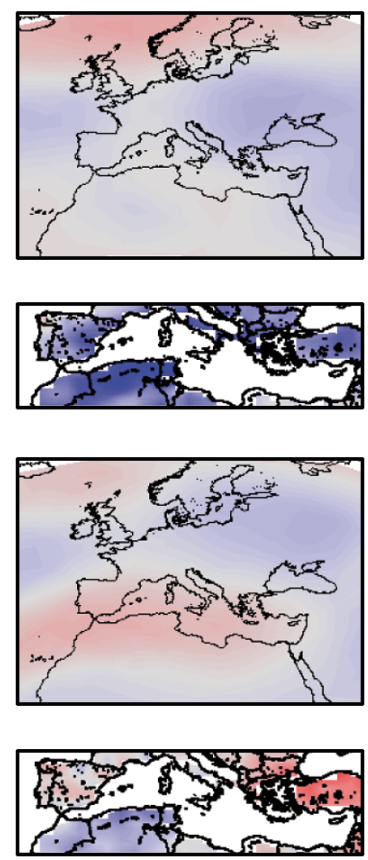

Fig. 9. Canonical loadings as in Fig. 2, but for consecutive dry days (CDD) during summer 
between large scale circulation and extreme dry spells that occur in summer (mainly in CNRM results) can be attributed to local scale convection (Bartzokas et al. 2003), which is unresolved by RCMs.

In general, for winter, spring and autumn, CNRM results compare well with $\mathrm{C} 4 \mathrm{I}$, revealing almost the same circulation pattern, though the CDD distribution presents intense spatial variability. The loadings for KNMI are weak and no specific large scale pattern seems to form.

\section{CONCLUSIONS}

Three RCMs along with their parental GCMs were evaluated and inter-compared with respect to their ability to reproduce large-scale circulation patterns of the upper air associated with 2 precipitation (PQ95 and CDD) and 2 temperature extreme indices (TXQ90 and TNQ10) in the Mediterranean region. Two of them (C4I-RCA3 and KNMI-RAMCO) are driven by the same GCM (ECHAM5) and the third one (CNRMAladin) by a different GCM (ARPEGE).

The observed upper air large scale patterns related to climate extremes in the Mediterranean are not reproduced in all seasons. In many cases the models display patterns of extreme climate indices which are not consistent with the accompanying upper level circulation.

CNRM provides more coherent results across the Mediterranean region and is more capable for simulating temperature extremes but less for precipitation. Furthermore, all models display substantial deficiencies in simulating precipitation extremes. This applies in particular the representation of the summer extremes, which are mostly of convective origin. C4I provides better results in summer and KNMI in the transient seasons. CNRM and KNMI exhibit more coherent patterns for TXQ90 in summer and TNQ10 in winter. C4I provides more consistent results for CDD in summer, with high loadings. The RCCA results demonstrate that all $3 \mathrm{RCM} / \mathrm{GCM}$ couples perform better for temperature than for precipitation extremes.

In summer, the ability of all 3 models is limited, possibly because the strength of the large-scale atmospheric flow decreases, the control exerted by the lateral boundary conditions is weaker and the nested models are more free to deviate from the large scale of the driving field, as discussed by Alexandru et al. (2007) and Sanchez-Gomez et al. (2009).

Overall, the results on the links of atmospheric circulation with climate extremes, as produced by the 3 couples of global and regional climate models, exhibit differences and do not inter-compare well. This can be attributed to the fact that since the simulations are based on downscaling of different GCMs with differ- ent systematic biases, RCM simulations also have a range of errors inherited from the GCMs, besides the different formulation and experimental setup of each RCM (Kostopoulou et al. 2009, Zanis et al. 2009).

The comparison between the sets with different driving GCMs demonstrates that CNRM/ARPEGE represents better the observed large-scale circulation patterns, suggesting the importance of these patterns in reproducing extremes. This is especially evident in winter for all indices, when the large scale circulation plays the most important role. The inter-comparison of the C4I and KNMI couples, driven by the same GCM (ECHAM5), reveals that they simulate similar large scale patterns, however, with different spatial distribution of canonical loadings of extreme indices. This is evidence of the role of the internal variability of each RCM as a source of uncertainty (Sanchez-Gomez et al. 2009), something more apparent in summer, when local factors prevail over the large scale circulation.

Although multivariate methods (such as RCCA) make assumptions of normality in the data, and extreme values are not normally distributed, the RCCA results for the observed datasets do not present inconsistencies between large scale and surface fields, contrary to the corresponding model results. These inconsistencies between general circulation patterns and the extreme patterns in the models could be due to the possible inability of the models to capture their relationship or the coexistence of other (thermo) dynamic factors governing climate variability in the Mediterranean region, such as the subsidence affecting the tropospheric static stability and, thus, precipitation (Eshel \& Farrell 2001).

Acknowledgements. This work was supported from EU-FP6 project ENSEMBLES-Ensemble Based prediction of climate change and its impacts (www.ensembles-eu.org), under contract GOCE-CT-2003-505539. We also acknowledge the gridded observational datasets from the ENSEMBLES project and the data providers in the ECA\&D project (http://eca.knmi.nl).

\section{LITERATURE CITED}

Alexandru A, de Elia R, Laprise R (2007) Internal variability in regional climate downscaling at the seasonal time scale. Mon Weather Rev 135:3221-3238

Baldi M, Dalu G, Maracchi G, Pasqui M, Cesarone F (2006) Heat waves in the Mediterranean: a local feature or a larger-scale effect? Int J Climatol 26:1477-1487

Bartzokas A, Lolis CJ, Metaxas DA (2003) A study on the intra-annual variation and the spatial distribution of precipitation amount and duration over Greece on a $10 \mathrm{~d}$ basis. Int J Climatol 23:207-222

Bergant K, Belda M, Halenka T (2007) Systematic errors in the simulation of European climate (1961-2000) with RegCM3 driven by NCEP/NCAR reanalysis. Int J Climatol 27:455-472

Chen CT, Knutson T (2008) On the verification and com- 
parison of extreme rainfall indices from climate models. J Clim 21:1605-1621

- Déqué M, Dreveton C, Braun A, Cariolle D (1994) The ARPEGE/IFS atmosphere model: a contribution to the French community climate modelling. Clim Dyn 10: 249-266

- Eshel G, Farrell BF (2000) Mechanisms of eastern Mediterranean rainfall variability. J Atmos Sci 57:3219-3232

Eshel G, Farrell BF (2001) Thermodynamics of eastern mediterranean rainfall variability. J Atmos Sci 58:87-92

- Flocas HA, Maheras P, Karacostas TS, Patrikas I, Anagnostopoulou C (2001) A 40 year climatological study of relative vorticity distribution over the Mediterranean. Int $\mathrm{J}$ Climatol 21:1759-1778

Fowler HJ, Ekström M, Blenkinsop S, Smith AP (2007) Estimating change in extreme European precipitation using a multimodel ensemble. J Geophys Res 112:D18104 doi:10. 1029/2007JD008619

Giannakopoulos C, Le Sager P, Bindi M, Moriondo M, Kostopoulou E, Goodess CM (2009) Climatic changes and associated impacts in the Mediterranean resulting from a $2{ }^{\circ} \mathrm{C}$ global warming. Global Planet Change 68:209-224

> Giorgi F, Mearns LO (1999) Introduction to special section: regional climate modeling revisited. J Geophys Res 104(D6):6335-6352 doi:10.1029/98JD02072

González I, Dejean C, Martin PGP, Baccini A (2008) CCA: an R package to extend Canonical Correlation Analysis. J Stat Softw 23(12). Available at: www.jstatsoft.org/v23/i12

Hanson CE, Palutikof JP, Livermore MTJ, Barring L and others (2007) Modelling the impact of climate extremes: an overview of the MICE project. Clim Change 81:163-177

- Hatzaki M, Flocas HA, Giannakopoulos C, Maheras P (2009) The impact of the Eastern Mediterranean teleconnection pattern on the Mediterranean climate. J Clim 22:977-992

Haylock MR, Goodess CM (2004) Interannual variability of European extreme winter rainfall and links with mean large-scale circulation. Int J Climatol 24:759-776

Haylock MR, Cawley GC, Harpham C, Wilby RL, Goodess CM (2006) Downscaling heavy precipitation over the United Kingdom: a comparison of dynamical and statistical methods and their future scenarios. Int J Climatol 26:1397-1415

> Haylock MR, Hofstra N, Klein Tank AMG, Klok EJ, Jones PD, New M (2008) A European daily high-resolution gridded dataset of surface temperature and precipitation for 1950-2006. J Geophys Res 113:D20119 doi:10.1029/2008 JD010201

Hofstra N, New M, McSweeney C (2009) The influence of interpolation and station network density on the distributions and trends of climate variables in gridded daily data. Clim Dyn 35:5 p 841-845

Jacobeit J (1987) Variations of trough positions and precipitation patterns in the Mediterranean area. Int $\mathrm{J}$ Climatol 7:453-476

Kjellström E, Bärring L, Gollvik S, Hansson U and others (2005) A 140-year simulation of European climate with the new version of the Rossby Centre regional atmospheric climate model (RCA3). SMHI Rep Meteorol Climatol 108, SMHI, Norrköping

Kostopoulou E, Jones PD (2005) Assessment of climate extremes in the Eastern Mediterranean. Meteorol Atmos Phys 89:69-85

Kostopoulou E, Jones PD (2007a) Comprehensive analysis of the climate variability in the eastern Mediterranean. I. Map pattern classification. Int J Climatol 27:1189-1214

Kostopoulou E, Jones PD (2007b) Comprehensive analysis of the climate variability in the eastern Mediterranean. II.
Relationships between atmospheric circulation patterns and surface climatic elements. Int J Climatol 27:1351-1371

Kostopoulou E, Tolika K, Tegoulias I, Giannakopoulos C, Somot S, Anagnostopoulou C, Maheras P (2009) Evaluation of a regional climate model using in situ temperature observations over the Balkan Peninsula. Tellus, Ser A, Dyn Meterol Oceanogr 61:357-370

Leurgans SE, Moyeed RA, Silverman BW (1993) Canonical correlation analysis when the data are curves. J R Stat Soc B 55:725-740

> Lloyd-Hughes B, Saunders MA (2002) A drought climatology for Europe. Int J Climatol 22:1571-1592

Lolis C, Metaxas DA, Bartzokas A (2008) On the intra-annual variability of atmospheric circulation in the Mediterranean region. Int J Climatol 28:1339-1355

> Lucas-Picher P, Caya D, de Elía R, Laprise R (2008) Investigation of regional climate models' internal variability with a 10-member ensemble of 10-year simulations over a large domain. Clim Dyn 31:927-940

> Maheras P, Xoplaki E, Kutiel H (1999) Wet and dry monthly anomalies across the Mediterranean basin and their relationship with circulation 1860-1990. Theor Appl Climatol 64:189-199

Maheras P, Flocas HA, Patrikas I, Anagnostopoulou C (2001) A 40 year objective climatology of surface cyclones in the Mediterranean region: spatial and temporal distribution. Int J Climatol 21:109-130

> Maheras P, Tolika K, Anagnostopoulou C, Vafiadis M, Patrikas I, Flocas HA (2004) On the relationships between circulation types and changes in rainfall variability in Greece. Int J Climatol 24:1695-1712

Maheras P, Flocas H, Tolika K, Anagnostopoulou C, Vafiadis $M$ (2006) Circulation types and extreme temperature changes in Greece. Clim Res 30:161-174

Meteorological Office (1962) Weather in the Mediterranean. I. General meteorology. HMSO, London

> Oikonomou C, Flocas HA, Hatzaki M, Nisantzi A, Asimakopoulos DN (2010) Relationship of extreme dry spells in Eastern Mediterranean with large-scale circulation. Theor Appl Climatol 100:137-151

> Pelly JL, Hoskins BJ (2003) A new perspective on blocking. J Atmos Sci 60:743-755

Prezerakos NG (1985) The northwest African depressions affecting the south Balkans. J Climatol 5:643-654

Radu R, Déqué M, Somot S (2008) Spectral nudging in a spectral regional climate model. Tellus, Ser A, Dyn Meterol Oceanogr 60:898-910

> Roeckner E, Brokopf R, Esch M, Giorgetta M and others (2006) Sensitivity of simulated climate to horizontal and vertical resolution in the ECHAM5 atmosphere model. J Clim 19:3771-3791

> Rummukainen M (2010) State-of-the-art with regional climate models. Wiley Interdisciplinary Reviews: Climate Change $1: 82-96$

Sanchez-Gomez E, Somot S, Déqué M (2009) Ability of an ensemble of regional climate models to reproduce weather regimes over Europe-Atlantic during the period 1961-2000. Clim Dyn 33:723-736

> Spanos SI, Maheras P, Karacostas T, Pennas P (2003) Objective climatology of $500-\mathrm{hPa}$ cyclones in central and east Mediterranean region during warm-dry period of the year. Theor Appl Climatol 75:167-178

Tolika K, Anagnostopoulou C, Maheras P, Vafiadis M (2008) Simulation of future changes in extreme rainfall and temperature conditions over the Greek area: a comparison of two statistical downscaling approaches. Global Planet Change 63:132-151 
Tolika K, Maheras P, Tegoulias I (2009) Extreme temperatures in Greece during 2007: could this be a 'return to the future'? Geophys Res Lett 36:L10813 doi:10.1029/2009GL038538

Valero F, Luna MY, Martín ML, Morata A, González-Rouco F (2004) Coupled modes of large-scale climatic variables and regional precipitation in the western Mediterranean in autumn. Clim Dyn 22:307-323

van der Linden P, Mitchell JFB (eds) (2009) ENSEMBLES: Climate change and its impacts: summary of research and results from the ENSEMBLES Project. Met Office Hadley Centre, Exeter

van Meijgaard E, van Ulft LH, van de Berg WJ, Bosveld FC, van den Hurk BJJM, Lenderink G, Siebesma AP (2008)

Editorial responsibility: Filippo Giorgi,

Trieste, Italy
The KNMI regional atmospheric climate model RACMO, version 2.1. KNMI Tech Rep 302. KNMI, De Bilt

van Ulden AP, van Oldenborgh GJ (2006) Large-scale atmospheric circulation biases and changes in global climate model simulations and their importance for climate change in Central Europe. Atmos Chem Phys 6:863-881

Vinod HD (1976) Canonical ridge and econometrics of joint production. J Econom 6:129-137

Zanis P, Douvis K, Kapsomenakis I, Kioutsioukis I, Melas D, Pal JS (2009) A sensitivity study of the Regional Climate Model (RegCM3) to the convective scheme with emphasis in central eastern and southeastern Europe. Theor Appl Climatol 97:327-337

Submitted: August 6, 2009; Accepted: December 21, 2010 Proofs received from author(s): March 11, 2011 